\title{
Journalistic Licensing as a Balance to Open-Source Journalism Practices
}

\section{John Dillon*}

Professor Emeritus, Murray State University, USA

At the risk of oversimplification, "open-source journalism" can be thought of as the technique of newsgathering, fact-checking, and news dissemination on the part of a wide variety of people, without necessary application of some stringent rules of Western journalism. Whereas news gathering has long been the domain of trained news reporters and editors -- with the goal of presentation of objective facts -- today's Internet environment includes bloggers and pundits whose main sourcing of information may well be borrowed or presented with a subjective agenda [1].

Many in the arena of media criticism suggest that open-sourcing of what should remain empirical social science corrodes the integrity of information. The argument goes that democracy, for one, cannot function properly if distortions and shallow observations are allowed in the public record. Information provision is the sacred duty of those who observe events firsthand, and who are trained to provide unbiased viewpoints. Others who attempt it may be merely "backseat drivers" leading us down the wrong road [2].

The question then becomes how information sharing might be balanced with the evolved standards of empirically-based, fairminded journalism. The answer may well lie in a practice which has been condemned for decades in Western thought: The certification or licensing of journalistic practitioners.

It is fair to say that there is no stopping the "democracy of distribution" that we see in philosophies of open-sourcing and the Digital Commons [3,4]. At the same time, there are legitimate concerns that misinformation cloaking itself as truth may bend reality in unfortunate ways.

Thus, a reappraisal of journalistic licensing should be attempted. The licensing (conceivably, "certification") of journalists by a watchdog non-governmental group would underscore journalism as a profession with standards to be met, and potentially sanctions to be employed should newsgathering norms be breached. The standards would most likely include higher education; journalistic training in newsgathering, interviewing and writing; passage of standards-based testing; internships; and perhaps even personal testimony to purity of goals in news transmission. Were normative standards greatly broken during actual practice, an individual journalist or editor would stand to be "disbarred." In fact, parallels to attorneys and their relationship to bar associations should not be dismissed [5].

Much thinking of the $20^{\text {th }}$ century was that licensing amounted to heavy-handed control of journalists, perhaps through governmental manipulation of political news reportage [6]. Others have seen a potential loss of independence among the news media that would "cheat us out of objective journalism" [7] and pave the way for a society blind to the cultural superstructure it has put in place.

However, the intricate new roles taken on by social media like Twitter and Facebook make it undeniable that unfettered information exchange will continue to be robust, if not frequently agenda-driven, on the part of ordinary citizens. Thus, the ability to distinguish a "branded and proven" journalist carries new merit in the $21^{\text {st }}$ century. There may be less detriment in licensing journalists than in not licensing some body of people who could be entrusted with upholding the torch of established journalistic norms. An imprimatur of sorts.

The argument is here made that a professional group -- such as the Society for Professional Journalists -- could administer accreditation in the journalistic arts should it choose to. The task need not fall to government, but to professionals in news provision (as at SPJ) who could carry the weight of both licensing and censure of journalists [8]. The mass media universe would be better served if the public understood that news provision was somewhat safeguarded by the checks and balances of serious journalists themselves.

\section{References}

1. Holesgrove A (2011) "Are We Being Cheated Out of Objective Journalism?" Business Insider

2. Palser B (2005) “Journalism's Backseat Drivers." American Journalism Review.

3. Suber P (2010) "Open Access Overview."

4. http://digitalcommons.bepress.com/

5. Baran S, Davis D (2006) Mass Communication Theory: Foundations, Ferment and Future. ( $4^{\text {th }}$ Edn) Thomson Education, Belmont, CA.

6. Press C, Verburg K (1988) American Politicians and Journalists. Foresman \& Co, Boston, Scott.

7. Ingram M (2011) “No, Licensing Journalists Isn't the Answer."Tech News and Analysis.

8. http://www.spj.org/mission.asp
*Corresponding author: John Dillon, Professor Emeritus, Murray State University, USA, Tel. 270 809-2387; E-mail: jdillon@murraystate.edu

Received January 07, 2012; Accepted January 07, 2012; Published January 09 2012

Citation: Dillon J (2012) Journalistic Licensing as a Balance to Open-Source Journalism Practices. J Mass Communicat Journalism 2:e108. doi:10.4172/21657912.1000e108

Copyright: (c) 2012 Dillon J. This is an open-access article distributed under the terms of the Creative Commons Attribution License, which permits unrestricted use, distribution, and reproduction in any medium, provided the original author and source are credited. 